\title{
Maternal Attachment Status, Mother-Child Emotion Talk, Emotion Understanding, and Child Conduct Problems
}

\author{
Brad M. Farrant, ${ }^{1,2}$ Murray T. Maybery, ${ }^{1}$ and Janet Fletcher ${ }^{1}$ \\ ${ }^{1}$ School of Psychology, The University of Western Australia, M304, 35 Stirling Highway, Crawley, WA 6009, Australia \\ ${ }^{2}$ Telethon Institute for Child Health Research, Centre for Child Health Research, The University of Western Australia, \\ P.O. Box 855, West Perth, WA 6872, Australia
}

Correspondence should be addressed to Brad M. Farrant; bfarrant@ichr.uwa.edu.au

Received 19 March 2013; Revised 15 July 2013; Accepted 19 July 2013

Academic Editor: Nobuo Masataka

Copyright (C) 2013 Brad M. Farrant et al. This is an open access article distributed under the Creative Commons Attribution License, which permits unrestricted use, distribution, and reproduction in any medium, provided the original work is properly cited.

\begin{abstract}
Conduct problems that emerge in childhood often persist into adolescence and are associated with a range of negative outcomes. It is therefore important to identify the factors that predict conduct problems in early childhood. The present study investigated the relations among maternal attachment status, mother-child emotion talk, child emotion understanding, and conduct problems in a sample of 92 (46 males) typically developing children ( $\mathrm{M}$ age $=61.3 \mathrm{months}, \mathrm{SD}=8.3$ months). The results support a model in which maternal attachment status predicts the level of appropriate/responsive mother-child emotion talk, which predicts child emotion understanding, which in turn negatively predicts child conduct problems. These findings further underline the developmental role of mother-child emotion talk as well as the importance of involving parents in programs designed to increase children's emotion understanding and/or decrease the incidence of conduct problems.
\end{abstract}

\section{Introduction}

Conduct problems involve atypical levels of oppositional behavior, aggression, stealing, and physical destructiveness [1]. These problems can begin in childhood [2] or adolescence [3] and may continue through the lifecycle [4]. Children who display conduct problems in the preschool years are at high risk of having problems that persist into adolescence (see [5] for a brief review). Indeed, this pattern, described as early starter [6], early onset [7], or life-course-persistent [8], is associated with the most negative prognosis including diagnoses of conduct disorder, oppositional defiant disorder, antisocial personality disorder, juvenile delinquency, school dropout, drug abuse, and criminality [1, 4, 9-11].

There is fairly broad theoretical agreement that conduct problems develop and are maintained through dynamic interactions among child, parental, peer, and environmental factors $[1,3,12-14]$. These factors include attachment patterns [15], emotion socialization [16], parenting [14], emotion understanding, and regulation skills [17] among others. These findings fit well with social-constructivist perspectives in which individual characteristics influence the parent-child interaction/socialisation which facilitate children's sociocognitive and behavioral development $[18,19]$.

Crittenden [20] argued that attachment patterns are selfprotective strategies that are initially learned in interactions with attachment figures in early childhood and continue to develop across the lifespan. Securely attached adults are comfortable depending on others, find it relatively easy to get close to other people, and are not worried or anxious about being abandoned [21]. They find it easier to identify and appropriately respond to the emotional signals and needs of others. Children with more insightful or emotionally attuned mothers are more likely to develop a secure attachment pattern [22].

Drawing on social-constructivist perspectives and attachment theory, it has been hypothesized that (a) adult attachment status influences the extent to which parents talk to their child about the child's emotions [20,23] with secure attachment associated with more appropriate/responsive talk about emotions [24, 25], (b) that parent-child emotion talk is an important aspect of socialization that facilitates children's emotion understanding [19], and (c) that emotion understanding reduces the incidence of conduct problems 
by enabling more advanced emotion and behavior regulation skills and a better understanding of what motivates the behavior of self and others [26].

We are unaware of any research that has directly examined hypothesis (a). However, there are findings indicating that mothers of securely attached preschool children are more likely to validate their child's negative emotions and that securely attached children are more likely to discuss negative emotions with their mothers [27]. Similarly, Farrar et al. [24] found that mothers of securely attached preschool girls were less likely to ignore their child's negative emotion talk and more likely to elaborate on it. Consistent with hypothesis (b), the findings of a number of studies provide support for a developmental relationship between parent-child emotion talk and children's emotion understanding [28-33]. These findings are also consistent with the argument that children's emotion understanding is facilitated by engaging in conversations in which they learn how to talk about emotions [30]. Consistent with hypothesis (c), there is evidence indicating that deficits in emotion understanding are associated with increased aggression [26, 28], poor school adjustment [34], behavior problems [35], and conduct problems more broadly [36].

Thus, the existing literature provides some support for developmental relations among attachment status, parentchild emotion talk, emotion understanding, and child conduct problems. However, there is a dearth of research investigating all these relations in the same study. The purpose of the present study was to use a social-constructivist approach to further our understanding of these relations in early childhood development. Drawing on previous work in this area, it was predicted that (1) mothers with secure attachment status would be likely to engage in more appropriate/ responsive mother-child emotion talk, (2) higher levels of mother-child emotion talk would be associated with better child emotion understanding, and (3) children with better emotion understanding would have fewer conduct problems. The hypothesized model is displayed in Figure 1. As both child age and gender have been found to be related to parentchild emotion talk [37], they were also included in the model.

\section{Method}

2.1. Participants. The data reported here represent part of a larger research project. All of the Australian children who participated in the present study spoke English as their first language. The participants were an unselected sample of children receiving regular education who were recruited via three primary schools spread across working class to upper middle class areas. Complete sets of the relevant data were available for 92 (46 males) children (81 Caucasians, 11 Asians) aged between 46 and 76 months $(\mathrm{M}=61.3$ months, $\mathrm{SD}=8.3$ months).

\subsection{Measures}

2.2.1. Maternal Attachment. Collins and Read's [38] adult attachment scale was used to measure maternal attachment status. The adult attachment scale comprised three subscales (depend, close, and anxiety), each containing six items. The depend subscale assesses the degree to which individuals are comfortable depending on others. The close subscale measures how comfortable the individual is being emotionally close to others, and the anxiety subscale assesses the degree to which the individual is worried or anxious about being abandoned. Participants rate how well each item describes them on a scale ranging from (1) not at all characteristic to (5) very characteristic, with a maximum possible score of 30 for each subscale. Previous research has found that the depend, close, and anxiety subscales have good construct validity and acceptable internal and test-retest reliability [38]. With the present sample of mothers, the depend $(\alpha=.82)$ and close ( $\alpha=.77$ ) subscales had acceptable reliability. The reliability of the anxiety subscale $(\alpha=.58)$ was lower than that found in previous research $(\alpha=.72 ;[38])$. However, inspection of the data did not reveal any systematic reason for this.

\subsubsection{Mother-Child Emotion Talk. Mother-child emotion} talk was measured using Dunsmore and Karn's [31] emotion language scale. This scale contains six items that assess how much time parents spend talking appropriately/responsively to their children about their emotions (e.g., I spend a lot of time talking to my children about why they feel the way they do). Mothers rated how well each item described them on a scale ranging from (1) not like me at all to (5) very much like me, with a maximum possible score of 30 . The emotion language scale has been found to have good construct validity [31]. The reliability of the scale $(\alpha=.62)$ with the present sample of mothers was similar to that found in previous research $(\alpha=.68 ;[31])$.

\subsubsection{Child Emotion Understanding. Children's emotion} understanding was measured with a combination of emotion matching, receptive emotion identification, expressive emotion identification, and emotional perspective taking tasks. These kinds of tasks are widely used and accepted in the literature as valid measures of emotion understanding [26, 27, 39-41]. There were two sets of tasks. The emotion matching, receptive emotion identification, and expressive emotion identification tasks measured the child's ability to identify the facial emotion expressions of scared, happy, sad, angry, surprised, and disgusted. Two versions of each task were created, each containing pictures of the same person showing each of the six emotions. One version of each task included pictures of a male and the other a female. The first task set contained the male version of the emotion matching task, the female version of the receptive emotion identification task, and the male version of the expressive emotion identification task. Gender was the opposite for each task in the second task set. All pictures were taken from Ekman and Friesen [42].

In the emotion matching task, the child was presented with a picture of a single face displaying the target emotion along with an array of the six pictures all of a different man or woman (one displaying the target emotion and five displaying the other emotions as distracters) in a random order. The child is then asked: "Can you point to the face that feels the same way as the man/woman?" The process was then repeated for each of the remaining emotions. In the receptive 


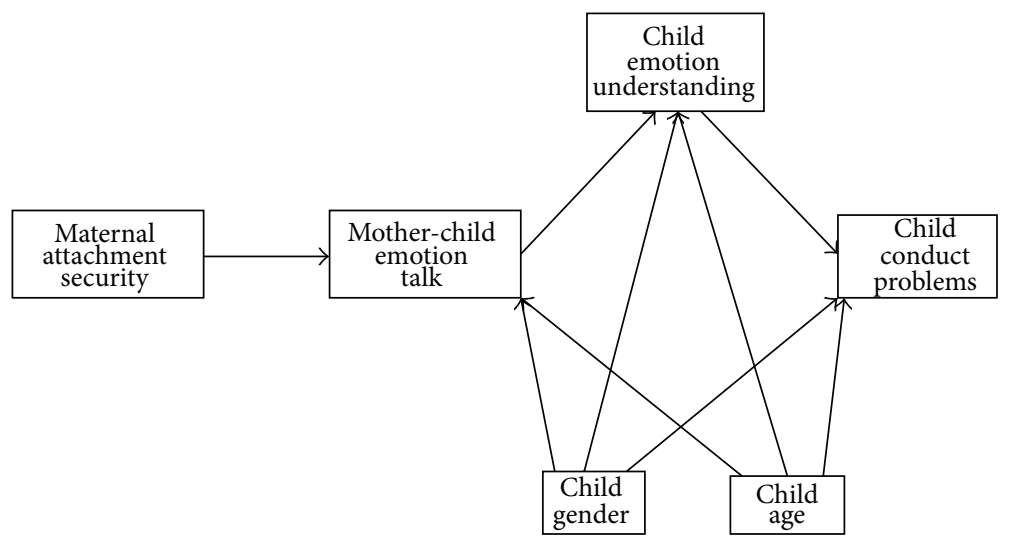

FIGURE 1: The hypothesized model including the control variables child age and child gender.

emotion identification task, the child was presented with an array of the six pictures and asked: "Can you point to the face?" The process was repeated for each of the six emotions (scared, happy, sad, angry, surprised, and disgusted). The position of each picture in the array was counterbalanced across trials. In the expressive emotion identification task, the child was presented with a single face and asked: "How does the man/woman feel-happy, sad, angry, scared, disgusted, or surprised?" The process was repeated for each of the six emotions.

Harwood and Farrar's [39] emotional perspective taking tasks were also used (see the appendix for detailed procedure). The child's ability to receptively and expressively identify two emotions (happy and sad) is initially assessed via an emotion labeling task. Then, after identifying his/her best friend, the child is told short stories involving him/herself and the identified friend in situations that would lead to the child and the friend experiencing different emotions (one happy, the other sad), and the child is asked to identify how s/he would feel and how the friend would feel.

2.2.4. Child Conduct Problems. The conduct problems scale of the strengths and difficulties questionnaire (SDQ; [43]) was completed by mothers and teachers. The conduct problems scale contains five items that assess the degree to which children display oppositional behavior, aggression, stealing, and antisocial behavior. Informants rate how well each item describes the child on a scale ranging from (0) not true, through (1) somewhat true, to (2) certainly true, with a maximum possible score of 10 for the scale. The SDQ is widely used [44], and the conduct problems scale has been found to have acceptable internal reliability, interrater agreement, and test-retest reliability [45]. For the present sample of teachers, the Cronbach's alpha for the scale (0.73) was acceptable. The reliability of the scale for the present sample of mothers $(\alpha=.41)$ was lower than that found in previous international $(\alpha=.63)$ [45] and Australian $(\alpha=.67)$ [46] research but inspection of the data did not reveal any systematic reason for this.

2.3. Procedure. Consent forms and information sheets were sent to parents/guardians of all kindergarten and preprimary children attending the three mainstream schools. Questionnaires were mailed to the primary caregivers (all mothers) who chose to participate, and completed questionnaires were mailed directly back to the researcher. The SDQ was completed by mothers and the children's kindergarten/primary school teachers. Children were individually tested in a quiet room at the child's school. The emotion understanding tasks were completed in a single session which lasted approximately 15 minutes. Approximately half of the children were randomly assigned to complete one version of the emotion understanding task set and the other half completed the other version.

2.4. Data Analytic Strategy. The hypothesized model was tested according to the conventional method for testing such a model within a structural equation model (SEM) framework [47, 48]. SEM was selected over traditional partial correlation or multiple regression analyses because SEM allows multiple pathways to be tested in the same analysis and it also provides goodness-of-fit statistics. Because of the relatively small sample size, a two-index strategy [49] involving the Incremental Fit Index (IFI; an incremental close-fit index) and the Standardized Root Mean-Square Residual (SRMR; an absolute close-fit index) was used to evaluate model fit [48]. In conjunction with $95 \%$ of normalized residuals being less than $|2.0|$, IFI values of $\geq .95$ and SRMR values of $\leq .08$ were considered indicative of a well-fitting model [48]. Maximum likelihood estimation was used as the basis for all SEM analyses. Child age and gender were included in the model as control variables, with possible paths indicated in Figure 1.

\section{Results}

Descriptive statistics are presented in Table 1. Child gender was coded as zero for male and one for female. In order to produce an index of maternal attachment security, median splits were used to create high and low groups on each of the adult attachment subscales (depend, close, and anxiety). Consistent with the secure attachment construct [21], mothers with high scores on the depend and close subscales and a low score on the anxiety subscale were given a score of three (secure 
TABLE 1: Mean and standard deviations of scores.

\begin{tabular}{lcc}
\hline Variable & M & SD \\
\hline Maternal attachment security (max. score 3) & 1.97 & 0.75 \\
Mother-child emotion talk (max. score 30) & 22.08 & 3.23 \\
Child emotion understanding (max. score 22) & 13.95 & 3.23 \\
Mother-rated child conduct problems (max. score 10) & 1.59 & 1.36 \\
Teacher-rated child conduct problems (max. score 10) & 0.70 & 1.34 \\
\hline
\end{tabular}

$N=92$.

attachment pattern), those with low scores on the depend and close subscales and a high score on the anxiety subscale were given a score of one (least secure attachment pattern), and those with the remaining patterns of scores on the subscales were given a score of two (moderately secure attachment pattern). The same pattern of results was found when an average of the three subscales (anxiety reverse scored) was used.

Children's responses to each emotion understanding question were scored as 1 (passed) or 0 (failed) giving a maximum possible score of 22. Emotion understanding scores were not significantly different between the two task sets $(t(90)=0.36, P=.72)$. Therefore, the results were collapsed across the two sets. Mothers' and teachers' ratings of children's conduct problems were significantly correlated. A measure of children's conduct problems across different contexts was created by averaging the $z$ scores for mothers' and teachers' ratings (similar overall patterns of results were obtained when just the mothers' or teachers' ratings of children's conduct problems were used). Multi-informant approaches such as this are preferable as they avoid single-source bias [50] and because different informants provide important information about children's behavior as it varies across different settings $[51,52]$.

Inspection of the correlations between the measures revealed that the main study variables were associated with each other in the expected directions and that the degree of multicollinearity between the predictor variables was acceptable (see Table 2). Prior to analysis, the data for the study variables were checked for multivariate outliers using Mahalanobis distance with $P<.001$ (critical value $=$ 22.46) but none was found. As hypothesized, significant positive correlations were observed between maternal attachment security and mother-child emotion talk and between motherchild emotion talk and child emotion understanding, and a significant negative correlation was observed between child emotion understanding and child conduct problems (see Table 2). Consistent with previous research, child gender was significantly correlated with mother-child emotion talk and child emotion understanding.

3.1. Evaluating Model Fit. The hypothesized model converged after five iterations with $\chi^{2}(6, N=92)=8.711, P=.191$, IFI $=$ .956 , and SRMR $=.069$. The unstandardized point estimates of the regression paths between child age and both motherchild emotion talk and conduct problems and between child gender and conduct problems were not significant; all other unstandardized point estimates were significant $(P<.05)$. Examination of the standardized residual covariances revealed one value over the $|2.0|$ mark between maternal attachment security and child conduct problems. This suggested that maternal attachment security had both direct and indirect effects on child conduct problems. To investigate this possibility, a regression path was added between maternal attachment security and child conduct problems.

The revised model converged after five iterations with $\chi^{2}(5, N=92)=5.083, P=.406, \mathrm{IFI}=.999$, and $\mathrm{SRMR}=.041$. The unstandardized point estimates of the regression paths between child age and both mother-child emotion talk and conduct problems and between gender and conduct problems were not significant; all other unstandardized point estimates were significant $(P<.05)$. All of the factor loadings were in the expected direction. No standardized residual covariances were over the $|2.0|$ mark. Standardized parameter estimates for the revised model are depicted in Figure 2. Therefore, because all indices were in the acceptable range, the revised model was considered to have acceptable model fit. As predicted, this model had significant regression paths between maternal attachment security and mother-child emotion talk, between mother-child emotion talk and child emotion understanding, and between child emotion understanding and child conduct problems (see Figure 2).

\section{Discussion}

The present study sought to further investigate the relations among maternal attachment status, mother-child emotion talk, emotion understanding, and conduct problems in early childhood. It was predicted that (1) mothers with secure attachment status would be more likely to engage in appropriate/responsive mother-child emotion talk, (2) higher levels of mother-child emotion talk would be associated with better child emotion understanding, and (3) children with better emotion understanding would have fewer conduct problems. The findings relevant to these hypotheses are discussed in the following sections.

4.1. Maternal Attachment Security and Mother-Child Emotion Talk. Maternal attachment security was associated with more mother-child emotion talk. This is consistent with the hypothesis that parents with secure attachment status are more comfortable with and therefore more likely to engage in appropriate/responsive parent-child emotion talk. The current study is the first to directly test this hypothesis.

Although the present results do not address the relationship between maternal attachment status and child attachment status, they do complement the findings of previous research which found that mothers of securely attached preschool girls were less likely to ignore their child's negative emotion talk and more likely to elaborate on it [24], that mothers of securely attached preschool children were more likely to validate their children's negative emotions [27], and that securely attached children were more likely to discuss negative emotions with their mothers [27]. Thus, the available evidence is consistent with the argument that the attachment 
TABLE 2: Correlations between variables.

\begin{tabular}{|c|c|c|c|c|c|c|}
\hline Variable & 1 & 2 & 3 & 4 & 5 & 6 \\
\hline (1) Maternal attachment security & - & & & & & \\
\hline (2) Mother-child emotion talk & $.39^{\dagger}$ & - & & & & \\
\hline (3) Child emotion understanding & $.22^{*}$ & $.28^{*}$ & - & & & \\
\hline (4) Child conduct problems & $-.25^{*}$ & $-.24^{*}$ & $-.25^{*}$ & - & & \\
\hline (5) Child Age in months & .02 & -.04 & $.37^{\dagger}$ & -.02 & - & \\
\hline (6) Child gender & -.07 & $.23^{*}$ & $.33^{\dagger}$ & -.04 & .04 & - \\
\hline
\end{tabular}

${ }^{*} P<.05,{ }^{\dagger} P<.005$, and $N=92$.

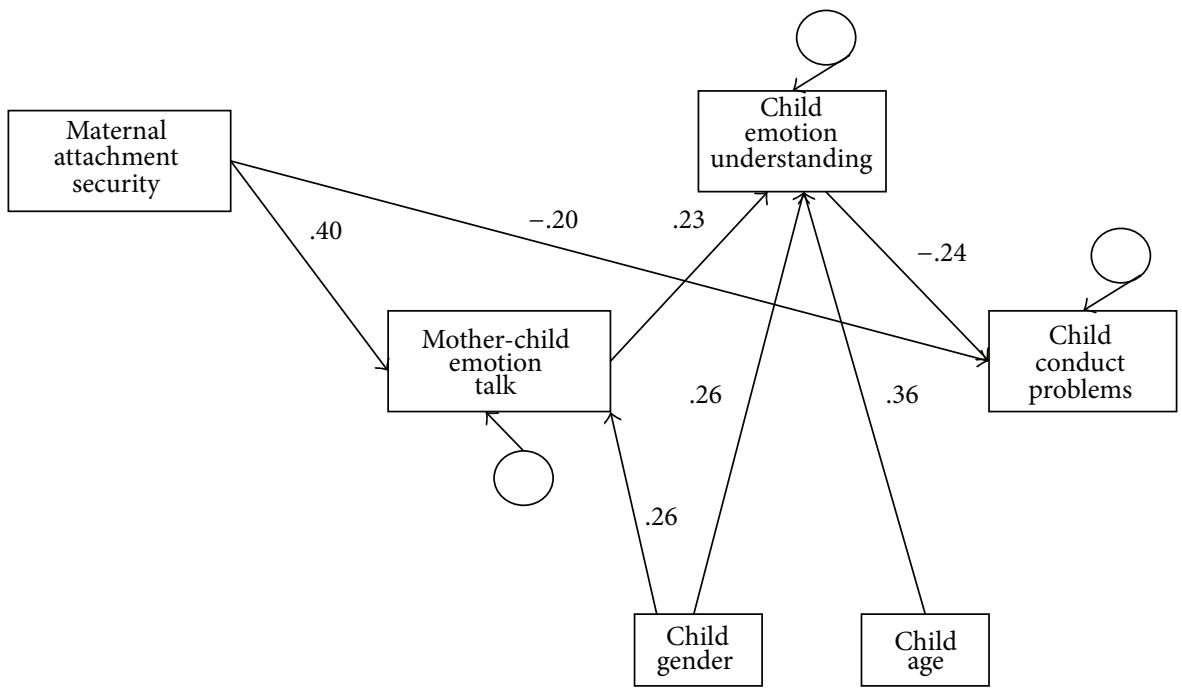

FIGURE 2: Standardized parameter estimates for the revised model. All reported estimates are the maximum likelihood standardized pointestimates. Only significant paths are shown. The unstandardized point estimates of the regression paths between child age and both motherchild emotion talk and conduct problems and between child gender and conduct problems were not significant; all other unstandardized point estimates were significant $(P<.05)$.

status of both parent and child influence parent-child communication about emotions $[23,24]$. Indeed, there is also evidence from research using the Adult Attachment Interview for the intergenerational transmission of secure attachment [53]. Children with more insightful or emotionally attuned mothers are more likely to develop a secure attachment pattern [22], and parent-child emotion talk may be one of the ways in which parents influence the ongoing development of children's attachment status $[24,25]$.

4.2. Mother-Child Emotion Talk, Emotion Understanding, and Conduct Problems. As hypothesized, higher levels of motherchild emotion talk were associated with better child emotion understanding. This finding is consistent with the results of previous research which found a developmental relationship between parent-child emotion talk and children's emotion understanding [28-33]. Thus, the available evidence suggests that parent-child emotion talk is an important aspect of socialization that facilitates children's emotion understanding [19]. In other words, children's emotion understanding is facilitated by engaging in conversations in which they learn how to talk about emotions [30]. Nevertheless, it is important to recognize that the current findings are also consistent with the possibility that other aspects of parent-child interaction/conversation provide important information that facilitates children's emotion understanding.

Furthermore, as hypothesized, in the present study a relationship was observed between emotion understanding and conduct problems such that children with better emotion understanding had fewer conduct problems. This finding is consistent with the argument that that emotion understanding reduces the incidence of conduct problems by enabling more advanced emotion and behavior regulation skills and a better understanding of what motivates the behavior of self and others [26]. Such a relationship between emotion understanding and conduct problems is also supported by previous research which found that deficits in emotion understanding are associated with increased aggression $[26,28]$, poor school adjustment [34], behavior problems [35], and conduct problems more broadly [36].

Therefore, the available evidence suggests that parents with secure attachment are more likely to engage in appropriate/responsive parent-child emotion talk, that higher levels of parent-child emotion talk are associated with better child emotion understanding, and that children with better emotion understanding have fewer conduct problems. However, it is important to note that this research is correlational in nature and correlation is not causation. Thus, even though 
we would hope that parents have more control over their emotions and behavior than their children do [2], some may argue for causation in the opposite direction from child to parent. On face value, it does seem plausible that child emotion understanding may influence the amount of parent-child emotion talk. However, this becomes less plausible in light of the current finding that child age was significantly associated with child emotion understanding but not with the amount of mother-child emotion talk. It also seems unlikely that mother-child emotion talk and children's conduct problems determine maternal attachment security especially as the latter was a measure of general tendencies across different relationships in the present study. Nevertheless, the findings of future training and/or intervention studies would help further clarify the causal nature of the relationships among maternal attachment status, parent-child emotion talk, emotion understanding, and conduct problems.

4.3. Child Gender. Female child gender was significantly positively associated with mother-child emotion talk and child emotion understanding in the current study. This is consistent with the findings of previous research and the metaanalysis by Leaper et al. [54] which found that mothers talk more in general to daughters than to sons. The current results also suggest that there is a gender effect on child emotion understanding over and above the effect of gender on motherchild emotion talk. However, there was no significant effect of child gender on conduct problems in the present study. Thus, it may be that there are gender differences in the relations among parent-child emotion talk, emotion understanding, and conduct problems. Unfortunately, sample size meant that it was not possible to conduct separate analyses for boys and girls in the current study. This represents a fruitful avenue for future research.

4.4. Implications, Strengths, and Limitations. Combining the results of previous research with the findings of the present study suggests the possibility of increasing children's emotion understanding and decreasing conduct problems by encouraging parent-child emotion talk. Indeed, a number of interventions for behavioral problems, from a range of theoretical perspectives, involve a focus on parent-child emotion talk $[55,56]$ sometimes in conjunction with a focus on teacher-child emotion talk [57]. There is also evidence supporting the efficacy of intervention programs that focus on younger children $[58,59]$. Thus, a promising avenue for future research would be to investigate whether an intervention/training program aimed solely at increasing parent-child emotion talk in early childhood (particularly the preschool years) would be protective in preventing the development of conduct problems by promoting children's emotion understanding or whether successful intervention requires attention to other aspects of parent-child interaction as well.

The limitations of the present study include the low reliability of the anxiety subscale of the adult attachment scale. While the use of a multi-informant design is one of the strengths of the current study, the use of maternal reports of maternal attachment and mother-child emotion talk are possible limitations. However, the significant positive correlations observed between scores on these measures and children's scores on the emotion understanding tasks provide some support for the validity of these maternal measures. Nevertheless, future research using broader measures of child conduct problems and multi-informant and/or observational data should further investigate the relationships observed in the current study. Future research should also investigate the relationship between parent and child attachment status using self-report measures of adult attachment and other measures such as the Adult Attachment Interview as well as the relations among attachment status, emotion regulation [60], social interaction patterns [61], and personality traits [62]. Our understanding of the relationships among maternal attachment status, parent-child emotion talk, emotion understanding, and conduct problems would also benefit from longitudinal research that measures these constructs at regular intervals from a point early in childhood.

\section{Conclusions}

The findings of the current study converge with the results of prior research in indicating that mothers with secure attachment are more likely to engage in appropriate/responsive parent-child emotion talk, that higher levels of motherchild emotion talk are associated with better child emotion understanding, and that children with better emotion understanding have fewer conduct problems. The present results also suggest that the relations among mother-child emotion talk, emotion understanding, and conduct problems may be augmented differently in boys and girls. Perhaps most importantly, the current findings add to the empirical evidence which suggests that interventions that increase the amount of parent-child emotion talk may provide an effective way to promote children's emotion understanding and prevent the development of conduct problems.

\section{Appendix}

\section{Detailed Procedure for Emotional Perspective Taking Tasks}

Initial Emotion Labeling Task. The child is shown a piece of paper with pictures of two faces: one happy, one sad (gender matched to that of the child). The experimenter points to one of the faces and asks: "How does s/he feel?" Then the experimenter points to other face and asks: "How does s/he feel?" (If the child is incorrect, the correct answer is provided and the task is repeated until the child agrees that the faces show the correct emotion.) Next, the child is shown another piece of paper on which the location of the faces has been switched; the experimenter asks the child: "Show me the happy face?" followed by "Show me the sad face?" (If the child is incorrect, the correct answer is provided and the task is repeated until the child points to the correct face for both emotions.)

Emotional Perspective Taking Task. The child is asked: "Who is your best friend?" (If the child does not respond, the child 
is asked "who do you like to play with?" If they provide more than one name, the first one they mention is used.) "Now I am going to tell you some short pretend stories about you and _. After each story, I will ask how you and _ _ would feel. I want you to point to the face that shows how you would each feel. If you think that the person would be happy, point to the happy face or say happy. If you think that the person would be sad, point to the sad face or say sad." "Ok, here is the first story, you and _ are playing with your toys and someone walks by and steps on them. Your favourite toy gets broken, but all of _ toys are okay. How does _ feel? How do you feel?" (If the child vocalises an answer other than happy or sad, the child is asked to point to the face that shows how the person would feel.) "Here is the second story, when you are out on the playground, everyone wants to play with you and no one wants to play with __. How do you feel? How does feel?"

The procedure for the second set of emotional PT tasks was identical to the first except that the stories were as follows: "You and _ both make houses out of blocks and then leave to get some more blocks. When you come back, someone has knocked down your house but _ house is still there. How does _ feel? How do you feel?", and "Someone in your class is having a birthday party. You are invited, but __ is not invited to go. How do you feel? How does _ feel?"

\section{Acknowledgments}

The authors wish to thank all of the children, families, and teachers for their generous support and participation in this study. They wish to particularly acknowledge the assistance received from the participants' teachers (Fleur Aris, Susan Bamblett, Chris Blamey, Emily Bradshaw, Sarah Bye, Karen Colkin, Julie Cummings, Martine Damon, Pamela Dow, Lesley Edelman, Julie Excell, Linda Goss, Michelle Green, Terri Hale, Martija Jukic, Jill Mitchell, Suzie Morrison, Christine Onley, Judith Rangihaeata, Deb Scarterfield, Jenny Smith, Lucy Stewart, Christine Tarnowy, Carolyn Vuletic, Jenny Whiting, Michelle Willis, Megan Wilson, and Veni Zeid).

\section{References}

[1] R. J. McMahon, K. C. Wells, and J. S. Kotler, "Conduct problems," in Treatment of Childhood Disorders, E. J. Mash and R. A. Barkley, Eds., pp. 137-268, Guilford Press, New York, NY, USA, 3rd edition, 2006.

[2] P. M. Cole, L. O. Teti, and C. Zahn-Waxler, "Mutual emotion regulation and the stability of conduct problems between preschool and early school age," Development and Psychopathology, vol. 15, no. 1, pp. 1-18, 2003.

[3] A. M. Klahr, M. McGue, W. G. Iacono, and S. A. Burt, "The association between parent-child conflict and adolescent conduct problems over time: results from a longitudinal adoption study," Journal of Abnormal Psychology, vol. 120, no. 1, pp. 46-56, 2011.

[4] J. H. Satterfield, K. J. Faller, F. M. Crinella, A. M. Schell, J. M. Swanson, and L. D. Homer, "A 30-year prospective followup study of hyperactive boys with conduct problems: adult criminality," Journal of the American Academy of Child and Adolescent Psychiatry, vol. 46, no. 5, pp. 601-610, 2007.
[5] S. B. Campbell, "Behavior problems in preschool children: a review of recent research," Journal of Child Psychology and Psychiatry and Allied Disciplines, vol. 36, no. 1, pp. 113-149, 1995.

[6] G. Patterson, D. Capaldi, and L. Bank, "An early starter model for predicting delinquency," in The Development and Treatment of Childhood Aggression, D. J. Pepler and K. H. Rubin, Eds., pp. 139-168, Lawrence Erlbaum, Hillsdale, NJ, USA, 1991.

[7] C. Webster-Stratton and M. Hammond, "Treating children with early-onset conduct problems: a comparison of child and parent training interventions," Journal of Consulting and Clinical Psychology, vol. 65, no. 1, pp. 93-109, 1997.

[8] T. E. Moffitt, "Adolescence-limited and life-course-persistent antisocial behavior: a developmental taxonomy," Psychological Review, vol. 100, no. 4, pp. 674-701, 1993.

[9] S. B. Campbell, "Longitudinal studies of active and aggressive preschoolers: individual differences in early behavior and outcomes," in InternalizIng and ExternalizIng Expressions of Dysfunction, D. Cicchetti and S. L. Toth, Eds., pp. 57-89, Lawrence Erlbaum, Hillsdale, NJ, USA, 1991.

[10] R. Loeber, "Antisocial behavior: more enduring than changeable?" Journal of the American Academy of Child and Adolescent Psychiatry, vol. 30, no. 3, pp. 393-397, 1991.

[11] H. L. Gelhorn, J. T. Sakai, R. K. Price, and T. J. Crowley, "DSM-IV conduct disorder criteria as predictors of antisocial personality disorder," Comprehensive Psychiatry, vol. 48, no. 6, pp. 529-538, 2007.

[12] C. Webster-Stratton and M. Reid, "The Incredible Years parents, teachers, and children training series: a multifaceted treatment approach for young children with conduct disorders," in Evidence-Based Psychotherapies for Children and Adolescents, J. R. Weisz and A. E. Kazdin, Eds., pp. 194-210, Guilford Press, New York, NY, USA, 2nd edition, 2010.

[13] C. Zahn-Waxler, E. A. Shirtcliff, and K. Marceau, "Disorders of childhood and adolescence: gender and psychopathology," Annual Review of Clinical Psychology, vol. 4, pp. 275-303, 2008.

[14] S. A. Denham, E. Workman, P. M. Cole, C. Weissbrod, K. T. Kendziora, and C. Zahn-Waxler, "Prediction of externalizing behavior problems from early to middle childhood: the role of parental socialization and emotion expression," Development and Psychopathology, vol. 12, no. 1, pp. 23-45, 2000.

[15] J. Vando, D. M. Rhule-Louie, R. J. McMahon, and S. J. Spieker, "Examining the link between infant attachment and child conduct problems in grade 1," Journal of Child and Family Studies, vol. 17, no. 5, pp. 615-628, 2008.

[16] J. N. Cunningham, W. Kliewer, and P. W. Garner, "Emotion socialization, child emotion understanding and regulation, and adjustment in urban African American families: differential associations across child gender," Development and Psychopathology, vol. 21, no. 1, pp. 261-283, 2009.

[17] C. Webster-Stratton and M. J. Reid, “Treating conduct problems and strengthening social and emotional competence in young children: the dina dinosaur treatment program," Journal of Emotional and Behavioral Disorders, vol. 11, no. 3, pp. 130-143, 2003.

[18] D. A. Murphey, "Constructing the child: relations between parents' beliefs and child outcomes," Developmental Review, vol. 12, no. 2, pp. 199-232, 1992.

[19] N. Eisenberg, A. Cumberland, and T. L. Spinrad, "Parental socialization of emotion," Psychological Inquiry, vol. 9, no. 4, pp. 241-273, 1998.

[20] P. M. Crittenden, Raising Parents: Attachment, Parenting and Child Safety, Willan Publishing, Devon, UK, 2008. 
[21] C. Hazan and P. Shaver, "Romantic love conceptualized as an attachment process," Journal of Personality and Social Psychology, vol. 52, no. 3, pp. 511-524, 1987.

[22] D. Oppenheim and N. Koren-Karie, "Mothers' insightfulness regarding their children's internal worlds: the capacity underlying secure child-mother relationships," Infant Mental Health Journal, vol. 23, no. 6, pp. 593-605, 2002.

[23] I. Bretherton, "From dialogue to internal working models: the co-construction of self in relationships," in Memory and Affect in Development, pp. 237-263, Lawrence Erlbaum, Hillsdale, NJ, USA, 1993.

[24] M. J. Farrar, L. G. Fasig, and M. K. Welch-Ross, "Attachment and emotion in autobiographical memory development," Journal of Experimental Child Psychology, vol. 67, no. 3, pp. 389-408, 1997.

[25] R. A. Thompson, D. J. Laible, and L. L. Ontai, "Early understandings of emotion, morality, and self: developing a working model," Advances in Child Development and Behavior, vol. 31, pp. 137-171, 2004.

[26] S. A. Denham, S. Caverly, M. Schmidt et al., "Preschool understanding of emotions: contributions to classroom anger and aggression," Journal of Child Psychology and Psychiatry and Allied Disciplines, vol. 43, no. 7, pp. 901-916, 2002.

[27] S. F. Waters, E. A. Virmani, R. A. Thompson, S. Meyer, H. A. Raikes, and R. Jochem, "Emotion regulation and attachment: unpacking two constructs and their association," Journal of Psychopathology and Behavioral Assessment, vol. 32, no. 1, pp. 37-47, 2010.

[28] P. W. Garner, J. C. Dunsmore, and M. Southam-Gerrow, "Mother-child conversations about emotions: linkages to child aggression and prosocial behavior," Social Development, vol. 17, no. 2, pp. 259-277, 2008.

[29] D. Laible and J. Song, "Constructing emotional and relational understanding: the role of affect and mother-child discourse," Merrill-Palmer Quarterly, vol. 52, no. 1, pp. 44-69, 2006.

[30] T. P. Racine, J. I. M. Carpendale, and W. Turnbull, "Parentchild talk and children's understanding of beliefs and emotions," Cognition and Emotion, vol. 21, no. 3, pp. 480-494, 2007.

[31] J. C. Dunsmore and M. A. Karn, "Mothers' beliefs about feelings and children's emotional understanding," Early Education and Development, vol. 12, no. 1, pp. 117-138, 2001.

[32] J. Dunn, J. Brown, and L. Beardsall, "Family talk about feeling states and children's later understanding of others' emotions," Developmental Psychology, vol. 27, no. 3, pp. 448-455, 1991.

[33] S. A. Denham, D. Zoller, and E. A. Couchoud, "Socialization of preschoolers' emotion understanding," Developmental Psychology, vol. 30, no. 6, pp. 928-936, 1994.

[34] A. Shields, S. Dickstein, R. Seifer et al., "Emotional competence and early school adjustment: a study of preschoolers at risk," Early Education and Development, vol. 12, no. 1, pp. 73-96, 2001.

[35] S. L. Kidwell, M. E. Young, L. D. Hinkle, A. D. Ratliff, M. E. Marcum, and C. N. Martin, "Emotional competence and behavior problems: differences across preschool assessment of attachment classifications," Clinical Child Psychology and Psychiatry, vol. 15, no. 3, pp. 391-406, 2010.

[36] R. J. Casey, "Emotional competence in children with externalizing and internalizing disorders," in Emotional Development in Atypical Children, M. Lewis and M. W. Sullivan, Eds., pp. 161183, Lawrence Erlbaum, Hillsdale, NJ, USA, 1996.

[37] C. A. Cervantes and M. A. Callanan, "Labels and explanations in mother-child emotion talk: age and gender differentiation," Developmental Psychology, vol. 34, no. 1, pp. 88-98, 1998.
[38] N. L. Collins and S. J. Read, "Adult attachment, working models, and relationship quality in dating couples," Journal of Personality and Social Psychology, vol. 58, no. 4, pp. 644-663, 1990.

[39] M. D. Harwood and M. J. Farrar, "Conflicting emotions: the connection between affective perspective taking and theory of mind," British Journal of Developmental Psychology, vol. 24, no. 2, pp. 401-418, 2006.

[40] R. Ensor and C. Hughes, "More than talk: relations between emotion understanding and positive behaviour in toddlers," British Journal of Developmental Psychology, vol. 23, no. 3, pp. 343-363, 2005.

[41] M. B. P. Rivera and J. C. Dunsmore, "Mothers' acculturation and beliefs about emotions, mother-child emotion discourse, and children's emotion understanding in Latino families," Early Education and Development, vol. 22, no. 2, pp. 324-354, 2011.

[42] P. Ekman and W. V. Friesen, Pictures of Facial Affect, Consulting Psychologists Press, Palo Alto, Calif, USA, 1976.

[43] R. Goodman, "The strengths and difficulties questionnaire: a research note," Journal of Child Psychology and Psychiatry and Allied Disciplines, vol. 38, no. 5, pp. 581-586, 1997.

[44] A. Goodman and R. Goodman, "Population mean scores predict child mental disorder rates: validating SDQ prevalence estimators in Britain," Journal of Child Psychology and Psychiatry and Allied Disciplines, vol. 52, no. 1, pp. 100-108, 2011.

[45] R. Goodman, "Psychometric properties of the strengths and difficulties questionnaire," Journal of the American Academy of Child and Adolescent Psychiatry, vol. 40, no. 11, pp. 1337-1345, 2001.

[46] D. Mellor, "Normative data for the strengths and difficulties questionnaire in Australia," Australian Psychologist, vol. 40, no. 3, pp. 215-222, 2005.

[47] K. A. Bollen, Structural Equations with Latent Variables, Wiley Series in Probability and Mathematical Statistics Applied Probability and Statistics Section, John Wiley \& Sons, Oxford, UK, 1989.

[48] G. E. Gignac, "Self-reported emotional intelligence and life satisfaction: testing incremental predictive validity hypotheses via structural equation modeling (SEM) in a small sample," Personality and Individual Differences, vol. 40, no. 8, pp. 15691577, 2006.

[49] L.-T. Hu and P. M. Bentler, "Cutoff criteria for fit indexes in covariance structure analysis: conventional criteria versus new alternatives,' Structural Equation Modeling, vol. 6, no. 1, pp. 1$55,1999$.

[50] T. Lewis, J. Kotch, R. Thompson et al., "Witnessed violence and youth behavior problems: a multi-informant study," American Journal of Orthopsychiatry, vol. 80, no. 4, pp. 443-450, 2010.

[51] E. Youngstrom, R. Loeber, and M. Stouthamer-Loeber, "Patterns and correlates of agreement between parent, teacher, and male adolescent ratings of externalizing and internalizing problems," Journal of Consulting and Clinical Psychology, vol. 68, no. 6, pp. 1038-1050, 2000.

[52] J. M. Nelson and H. R. Harwood, "A meta-analysis of parent and teacher reports of depression among students with learning disabilities: evidence for the importance of multi-informant assessment," Psychology in the Schools, vol. 48, no. 4, pp. 371384, 2011.

[53] M. H. Van Ijzendoorn, "Adult attachment representations, parental responsiveness, and infant attachment: a meta-analysis on the predictive validity of the adult attachment interview," Psychological Bulletin, vol. 117, no. 3, pp. 387-403, 1995. 
[54] C. Leaper, K. J. Anderson, and P. Sanders, "Moderators of gender effects on parents' talk to their children: a meta-analysis," Developmental Psychology, vol. 34, no. 1, pp. 3-27, 1998.

[55] H. Chambers, J. Amos, S. Allison, and L. Roeger, "Parent and child therapy: an attachment-based intervention for children with challenging problems," Australian and New Zealand Journal of Family Therapy, vol. 27, no. 2, pp. 68-74, 2006.

[56] S. S. Havighurst, K. R. Wilson, A. E. Harley, M. R. Prior, and C. Kehoe, "Tuning in to Kids: improving emotion socialization practices in parents of preschool children-findings from a community trial," Journal of Child Psychology and Psychiatry and Allied Disciplines, vol. 51, no. 12, pp. 1342-1350, 2010.

[57] C. E. Izard, K. A. King, C. J. Trentacosta et al., "Accelerating the development of emotion competence in Head Start children: effects on adaptive and maladaptive behavior," Development and Psychopathology, vol. 20, no. 1, pp. 369-397, 2008.

[58] C. Webster-Stratton, J. Rinaldi, and J. M. Reid, "Long-term outcomes of Incredible Years parenting program: predictors of adolescent adjustment," Child and Adolescent Mental Health, vol. 16, no. 1, pp. 38-46, 2011.

[59] E. V. Brestan and S. M. Eyberg, "Effective psychosocial treatments of conduct-disordered children and adolescents: 29 years, 82 studies, and 5,272 kids," Journal of Clinical Child Psychology, vol. 27, no. 2, pp. 180-189, 1998.

[60] R. R. Kobak, H. E. Cole, R. Ferenz-Gillies, W. S. Fleming, and W. Gamble, "Attachment and emotion regulation during mother-teen problem solving: a control theory analysis," Child Development, vol. 64, no. 1, pp. 231-245, 1993.

[61] M.-C. O. Tidwell, H. T. Reis, and P. R. Shaver, "Attachment, attractiveness, and social interaction: a diary study," Journal of Personality and Social Psychology, vol. 71, no. 4, pp. 729-745, 1996.

[62] P. R. Shaver and K. A. Brennan, "Attachment styles and the, "Big Five" personality traits: their connections with each other and with romantic relationship outcomes," Personality and Social Psychology Bulletin, vol. 18, no. 5, pp. 536-545, 1992. 

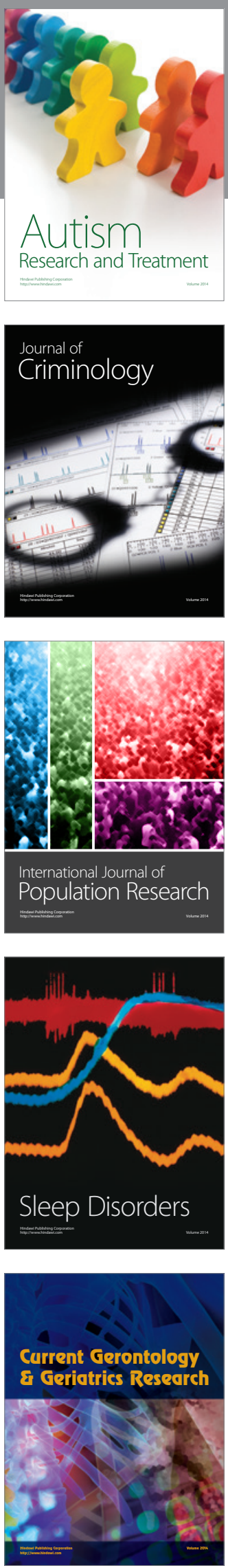
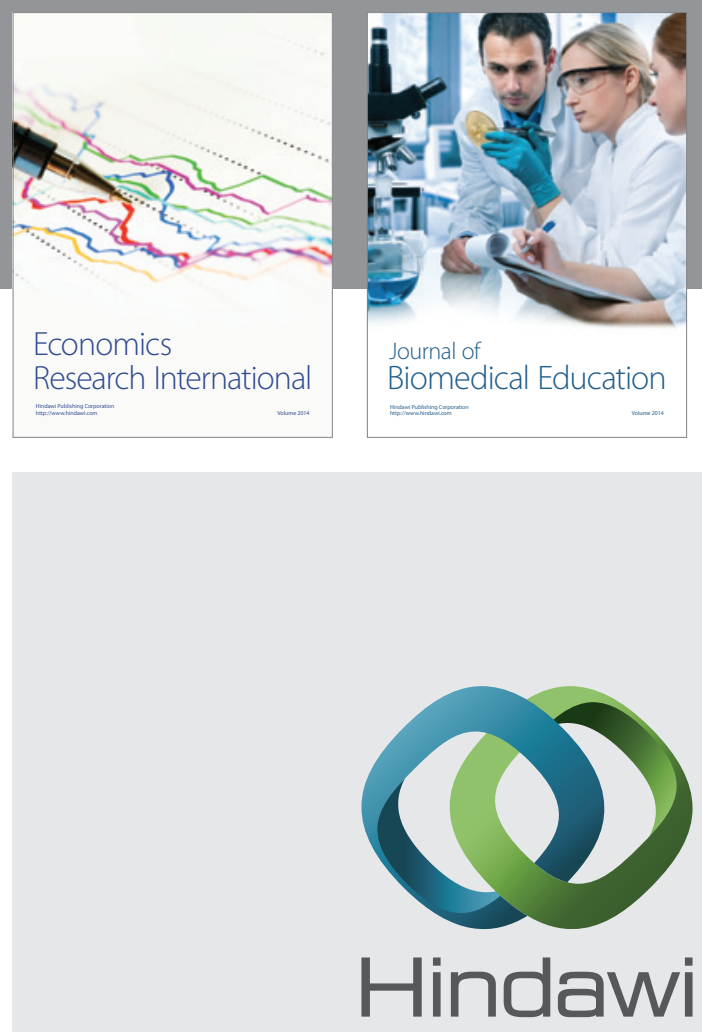

Submit your manuscripts at

http://www.hindawi.com
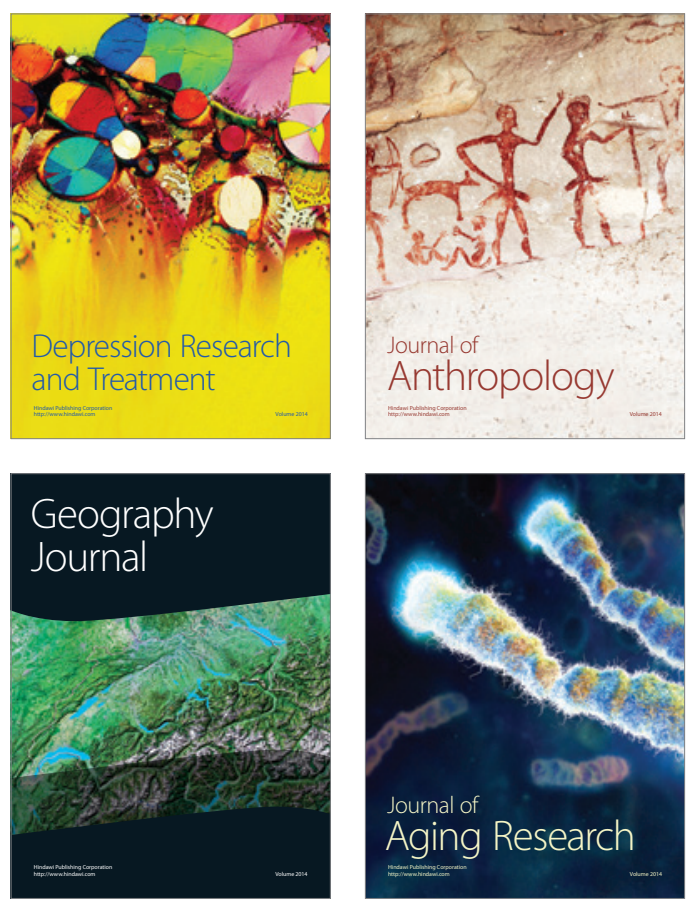
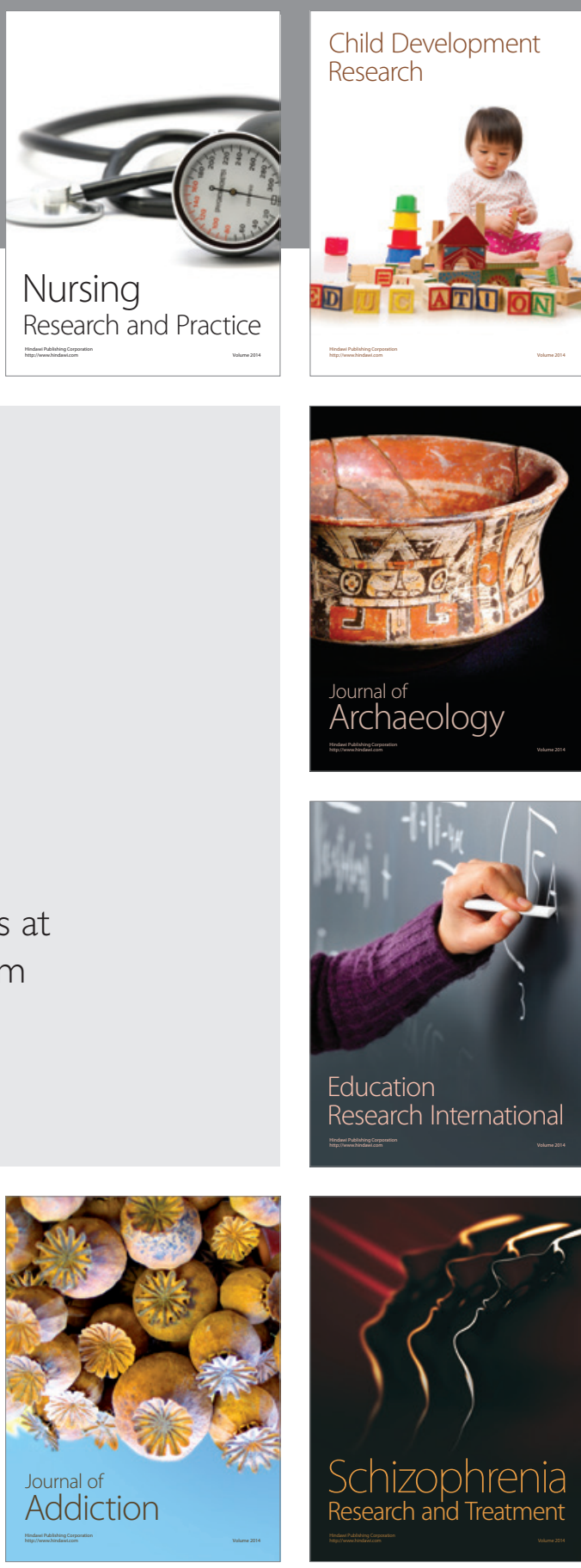

(D)
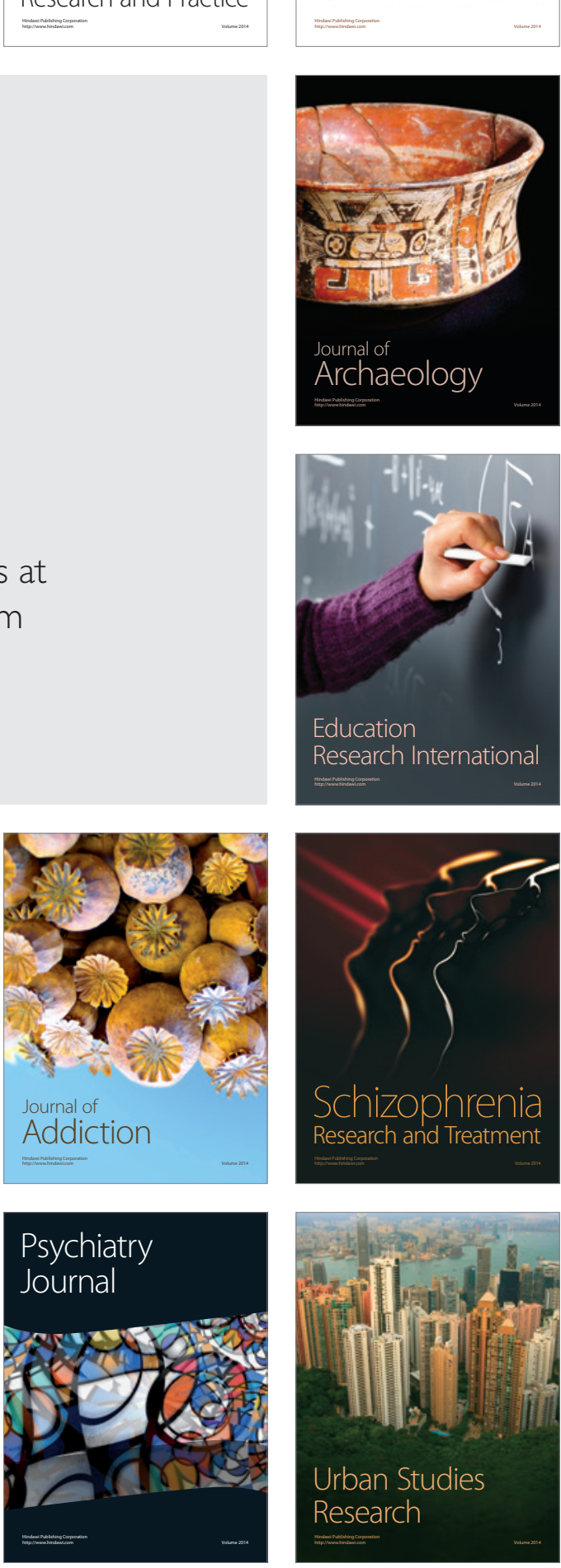